\title{
LATENT HEAT DETERMINATION FROM COOLING CURVES DURING SOLIDIFICATION OF METALS BY AN ALTERNATIVE METHOD CONSIDERING THE METAL AND MOLD COOLING PROCESSES *
}

Carlos Gonzalez Rivera ${ }^{1}$ Adrian Manuel Amaro Villeda ${ }^{2}$ Marco Aurelio Ramirez Argaez ${ }^{3}$

\begin{abstract}
An alternative cooling curve analysis method focused on the experimental determination of the latent heat of phase changes and phase transformation kinetics is proposed in this work.

The method analyses the cooling process of a metallic sample, initially liquid that is contained into a cylindrical metallic mold, both of known weight, thermally isolated at its top and bottom. The method is based on an energy balance associated with the experimental measurement of the temperature change of the sample and the mold during their cooling process. From the numerical processing of the cooling curves, are obtained approximate values of the acting global heat transfer coefficient as a function of temperature in order to describe quantitatively the energy exchange of the metal/mold system with its surroundings. These relationships and other experimental data are used to process the cooling curve of the sample and the mold during solidification, in order to obtain the latent heat of solidification. The method was applied experimentally to zinc and tin of commercial purity, initially liquids and contained into stainless steel molds in order to determine its ability to measure the latent heat of solidification. The obtained results suggests that this method shows a good potential to characterize the solidification of metals.
\end{abstract}

Keywords: Solidification, Kinetics; Cooling curve analysis.

1 Professor, Universidad Nacional Autónoma de México/ Metallurgical Engineering Department, Facultad de Química, Mexicocity, Mexico.

2 Professor, Universidad Nacional Autónoma de México/ Metallurgical Engineering Department, Facultad de Química, Mexicocity, Mexico.

3 Professor, Universidad Nacional Autónoma de México/ Metallurgical Engineering Department, Facultad de Química, Mexicocity, Mexico. 


\section{INTRODUCTION}

Cooling curve analysis has played a fundamental role in the control of the metallurgical quality of metallic products obtained through processes that in some of its stages involve the solidification of liquid metal and especially in the production of castings in gray and nodular irons, as well as in cast aluminum alloys [1].

For that reason there has been interest in finding new ways of analyzing the cooling curves of metals and alloys during their solidification, giving rise to what are known as Computer Aided Cooling Curve Analysis (CA-CCA), historically represented by the Newton thermal analysis (NTA)[2,3] and the Fourier thermal analysis (FTA)[4].The importance of these methods lies in its ability to generate key information that makes it possible to understand, control and simulate through specialized software, various aspects of solidification and phase transformations in the solid state, of metals and alloys under specific process conditions.

In recent years there have been a new generation of methods enhancing and ameliorating the potential applications of CA-CCA [5-8]. A very relevant change occurred with the proposal of Gibbs and Mendez [5] who, for the first time created a method of quantitative characterization of solidification that did not depend on a zero reference curve but, was based on an energy conservation equation, opening a new avenue for the development of new CCA methods.

Accordingly the aim of this work is to explore an alternative cooling curve analysis method, based in energy conservation equations, that takes into account the thermal role of the metallic mold containing the sample of interest, on the cooling process of the integral system metal sample/mold in order to determine experimentally the latent heat of solidification of two different metals of commercial purity.

\section{MATERIAL AND METHODS}

\subsection{Description of the method}

The method analyses the cooling process of a metallic sample of known weight, initially liquid that is contained into a cylindrical metallic mold of known weight, thermally isolated at its top and bottom.

The method assumes that both metal and metallic mold starts their cooling process at the same time, and this cooling process, when there is no change of phase, can be described by eq. (1):

$$
\mathrm{m}_{\mathrm{M}} \mathrm{Cp}_{\mathrm{M}} \frac{\mathrm{dT}}{\mathrm{dt}_{\mathrm{M}}}+\mathrm{m}_{\mathrm{mo}} \mathrm{Cp}_{\mathrm{mo}} \frac{\mathrm{dT}}{\mathrm{dt}_{\mathrm{mo}}}=-\mathrm{hA} *\left(\mathrm{~T}_{\mathrm{M}}-\mathrm{T}_{0}\right)
$$

In Eq. (1) $\mathrm{m}$ is the weigth, $\mathrm{Cp}$ is the heat capacity and $\mathrm{dT} / \mathrm{dt}$ is the cooling rate, using the sub index $\mathrm{M}$ for the metal and mo for the mold, $\mathrm{h}$ is the global heat transfer coefficient, $A$ is the area of exchange, TM is the temperature of the metal and T0 is the room temperature. Eq. (1) shows that the system formed by the metallic sample and the mold change their enthalpies as a result of a heat flow transferred to their surroundings through the exchange area A during its cooling at a given cooling rate. The global heat transfer coefficient $h$ takes into account all the thermal resistances present in the heat transfer process from the sample to its surroundings including eventually air gap between sample and mold, refractory paint inner and external layers, thermal resistance of the metallic mold wall and combined radiation and convection heat transfer from the outer wall of the mold to the surroundings. This global heat transfer can be estimated numerically from eq. (1) and experimental 
information on the metallic sample and mold during it cooling process when the sample is fully liquid or solid (i.e. without change of phase) according with Eqs. (2) and (3)

$$
\begin{array}{r}
\mathrm{m}_{M} \mathrm{Cp}_{\mathrm{M}} \mathrm{dT}_{\text {sample }}=-\mathrm{hA}\left(\mathrm{T}_{\mathrm{M}}-\mathrm{T}_{\mathrm{o}}\right) \mathrm{dt}-\mathrm{m}_{\mathrm{Mo}} \mathrm{Cp}_{\mathrm{Mo}} \mathrm{dT} \mathrm{T}_{\text {mold }} \\
\frac{\mathrm{m}_{\mathrm{M}} \mathrm{Cp}_{\mathrm{M}} \mathrm{dT}_{\mathrm{M}}+\mathrm{m}_{\mathrm{Mo}} \mathrm{Cp} \mathrm{p}_{\mathrm{Mo}} \mathrm{dT}_{\mathrm{mold}}}{-\mathrm{A}\left(\mathrm{T}_{\mathrm{M}}-\mathrm{T}_{\mathrm{o}}\right) \mathrm{dt}}=\mathrm{h}
\end{array}
$$

Thus, using experimentally available data, that includes the weights and the cooling curves of the metal and the mold, the room temperature T0, and the area of heat transfer exchange for the sample and selected values for the heat capacities of the metal and the mold, allows the generation of values for the global heat transfer coefficient of the system under study as a function of temperature through the numerical processing of the experimental cooling curves. The numerical fitting of these data gives equations that describes how this parameter change as a function of temperature.

In order to know which parts of the cooling curves will be used to obtain $\mathrm{h}$, the time of start and end of solidification, tss and tes respectively are determined on the first derivative of the cooling curve of the metal using the conventional criteria used by NTA method [3]. In this way the cooling curve of the sample is divided in three sequential sections: Cooling of the liquid, solidification and cooling of the solid During solidification of the sample, that is between tss and tes the energy balance is:

$$
\mathrm{m}_{M} \mathrm{Cp}_{M} \frac{\mathrm{dT}}{\mathrm{dt}_{M}}=-\mathrm{hA}\left(\mathrm{T}_{\mathrm{M}}-\mathrm{T}_{\mathrm{o}}\right)-\mathrm{m}_{\mathrm{Mo}} \mathrm{Cp}_{\mathrm{Mo}} \frac{\mathrm{dT}}{\mathrm{dt}}{ }_{M o}+\mathrm{m}_{M} \mathrm{H}_{\mathrm{f}} \frac{\mathrm{dFs}}{\mathrm{dt}}
$$

In a time step $\Delta t$, energy balance is:

$$
\mathrm{m}_{\mathrm{M}} \mathrm{Cp}_{\mathrm{M}} \Delta \mathrm{T}_{\mathrm{M}}=-\mathrm{hA}\left(\mathrm{T}_{\mathrm{M}}-\mathrm{To}\right) \Delta \mathrm{t}-\mathrm{m}_{\mathrm{Mo}} \mathrm{Cp}_{\mathrm{Mo}} \Delta \mathrm{T}_{\mathrm{Mo}}+\mathrm{m}_{\mathrm{M}} \mathrm{H}_{\mathrm{f}} \Delta \mathrm{Fs}
$$

Using a simple Euler integration Scheme, Eq. (5) can be written as:

$$
\mathrm{m}_{\mathrm{M}} \mathrm{Cp}_{\mathrm{M}}\left(\mathrm{T}_{\mathrm{M}}^{\mathrm{t}+\Delta \mathrm{t}}-\mathrm{T}^{\mathrm{t}}\right)=-\mathrm{hA}\left(\mathrm{T}_{\mathrm{M}}^{\mathrm{t}+\Delta \mathrm{t}}-\mathrm{To}\right) \Delta \mathrm{t}-\mathrm{m}_{\mathrm{Mo}} \mathrm{Cp}_{\mathrm{Mo}}\left(\mathrm{T}_{\mathrm{Mo}}^{\mathrm{t}+\Delta \mathrm{t}}-\mathrm{T}_{\mathrm{Mo}}{ }^{\mathrm{t}}\right)+\mathrm{m}_{\mathrm{M}} \mathrm{H}_{\mathrm{f}}\left(\mathrm{Fs}^{\mathrm{t}+\Delta \mathrm{t}}-\right.
$$

The instantaneous latent heat released by the sample is given by:

$$
\begin{array}{r}
Q_{\text {Linst }=}-\mathrm{m}_{\mathrm{M}} \mathrm{Hf}\left(\mathrm{Fs}^{\mathrm{t}+\Delta \mathrm{t}}-\mathrm{Fs}^{\mathrm{t}}\right)=-\mathrm{hA}\left(\mathrm{T}_{\mathrm{M}}^{\mathrm{t}+\Delta \mathrm{t}}-\mathrm{To}\right) \Delta \mathrm{t}-\mathrm{m}_{\mathrm{Mo}} \mathrm{Cp}_{\mathrm{Mo}}\left(\mathrm{T}_{\mathrm{Mo}}^{\mathrm{t}+\Delta \mathrm{t}}-\mathrm{T}_{\mathrm{Mo}}{ }^{\mathrm{t}}\right)- \\
\mathrm{m}_{\mathrm{M}} \mathrm{Cp}_{\mathrm{M}}\left(\mathrm{T}_{\mathrm{M}}^{\mathrm{t}+\Delta \mathrm{t}}-\mathrm{T}_{\mathrm{M}}^{\mathrm{t}}\right)(7)
\end{array}
$$

Finally the latent heat of solidification can be obtained from ec. (8)

$$
\Delta \mathrm{H}_{\mathrm{f}}=\frac{\mathrm{Q}_{\mathrm{Ltot}}}{\mathrm{m}_{\mathrm{M}}}=\frac{1}{\mathrm{~m}_{\mathrm{M}}} \int_{\mathrm{tss}}^{\mathrm{tes}} \mathrm{Q}_{\text {Linst }} \mathrm{dt}
$$

\subsection{Experimental}

In order to establish the ability of the proposed method to determine the enthalpy of phase change during the solidification of metals and alloys, two pure metals were 
chosen among the metals that have been extensively studied in the past and their thermophysical properties are reported in the sources of thermodynamic data. Zinc and Tin were chosen as the metals under study due to their low melting point. Triplicate determinations on each metal were performed in order to also explore the reproducibility of the method

Preweighted amounts of metal of commercial purity were put into a SiC crucible and placed in an electric furnace in order to obtain a metal liquid bath. The cylindrical metallic, stainless steel 316 molds $(0.03 \mathrm{~m}$ inner diameter, $0.05 \mathrm{~m}$ in height, and $0.0015 \mathrm{~m}$ in thickness, covered with boron nitride) were heated in another furnace. Each preheated metallic mold was filled with liquid metal. Next, it was placed on a thermal analysis test stand, then it was thermally isolated at the top and bottom. In this stand, and in order to record the thermal history of the metal and the mold during cooling, two $0.0003 \mathrm{~m}$ diameter bore, type $\mathrm{K}$ thermocouple with alumina two bore insulator, $0.0015 \mathrm{~m} \mathrm{OD}$, were introduced, the first at the mid-height of the mold cavity at the center of the probe and the second was introduced into the lateral mold wall. The thermocouple output was converted from analog to digital by means of a data acquisition card, NI FieldPointcFP 1804, and recorded into a PC hard disk drive, for a numerical post-processing task. The experimental cooling curves were numerically processed using the method proposed in this work to determine the latent heat of solidification.

Table 1 shows the thermophysical data used during calculations, reported in References $[9,10]$ and Table 2 shows the experimental weights of the metallic samples and molds.

Table 1. Thermophysical data taken as a reference $(\triangle \mathrm{HF})$ and used during calculations (CpL and $\mathrm{CpS}$ ) reported in sources of thermodynamic data $[9,10]$, sub index $L$ and $S$ indicate solid and liquid metal respectively

\begin{tabular}{l|c|c|l}
\hline Metal & $\mathbf{T}_{\mathrm{f}}\left({ }^{\circ} \mathrm{C}\right)$ & $\begin{array}{l}\Delta \mathbf{H}_{\mathrm{F}} \text { Enthalpy of } \\
\text { fusion }(\mathbf{J} / \mathbf{K g})\end{array}$ & $\begin{array}{l}\mathbf{C p}, \text { Heat Capacity } \\
\left(\mathbf{J} / \mathbf{K g}^{\circ} \mathrm{C}\right)\end{array}$ \\
\hline $\mathrm{Zns}$ & 419.5 & $\begin{array}{l}111426+/- \\
1920\end{array}$ & $342.5+0.154 \times(\mathrm{T}+273)$ \\
\hline $\mathrm{Zn} \mathrm{L}$ & & & 480.2 \\
\hline $\mathrm{Sns}$ & 232.3 & $\begin{array}{l}59605+/- \\
1060\end{array}$ & $181.954+0.153 \times(\mathrm{T}+273)$ \\
\hline $\mathrm{Sn}$ & & & $292.325-0.078 \times(\mathrm{T}+273)$ \\
\hline
\end{tabular}

Subindex S: Solid ; Subindex L: Liquid

Table 2. Experimental weights of the metallic samples and molds

\begin{tabular}{l|c|c|c}
\hline Zinc & M1 & M 2 & M 3 \\
\hline Metalweigth (gr) & 214.8 & 223.92 & 212.48 \\
\hline Moldweigth (gr) & 240.97 & 239.11 & 242.56 \\
\hline Tin & M1 & M 2 & M 3 \\
\hline Metalweigth (gr) & 203.3 & 209.3 & 205 \\
\hline Moldweigth (gr) & 243.1 & 241.3 & 234.6 \\
\hline
\end{tabular}

M1:Sample 1;M2 : Sample 2; M3 : sample 3. 


\section{RESULTS AND DISCUSSION}

Fig. 1 shows the cooling curves of the metal and mold under study typically obtained during experimentation for zinc and Tin. In all cases the curves shows three cooling stages: A first stage of cooling of the liquid sample, where temperature continuously falls until the start of the second stage when solidification of the sample starts and the metal temperature is maintained at a nearly constant temperature as a result of the release of latent heat, and this trend continue until the end of solidification, when the release of latent heat stops and the metal temperature falls again continuously, during the third stage of cooling of the sample in the solid state.It can be seen that there are differences between the instantaneous temperature of the metal and the mold, but it can be observed a trend to maintain nearly constant this difference, during each one of the cooling stages and it can be also seen that this difference changes during the three stages and reaches its highest value during the solidification of the metal.

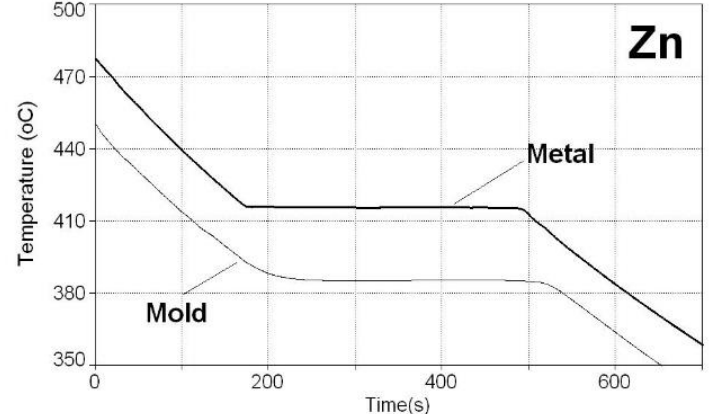

(a)

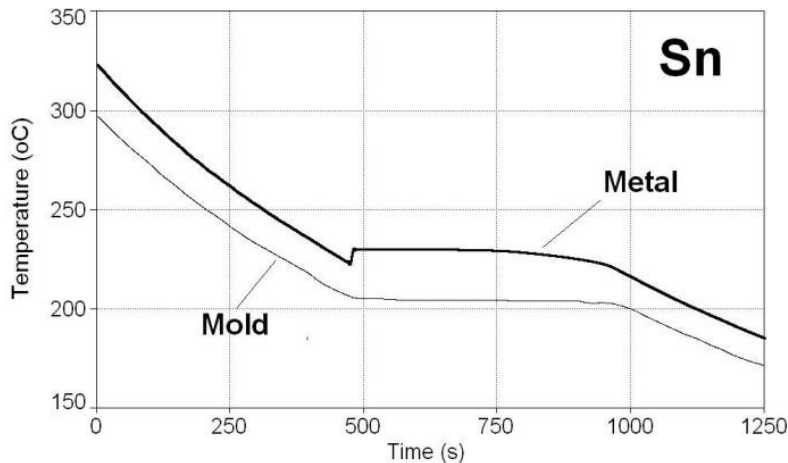

(b)

Figure 1. Typical cooling curves of the metal and the mold during their cooling process for (a)Zinc and (b) Tin

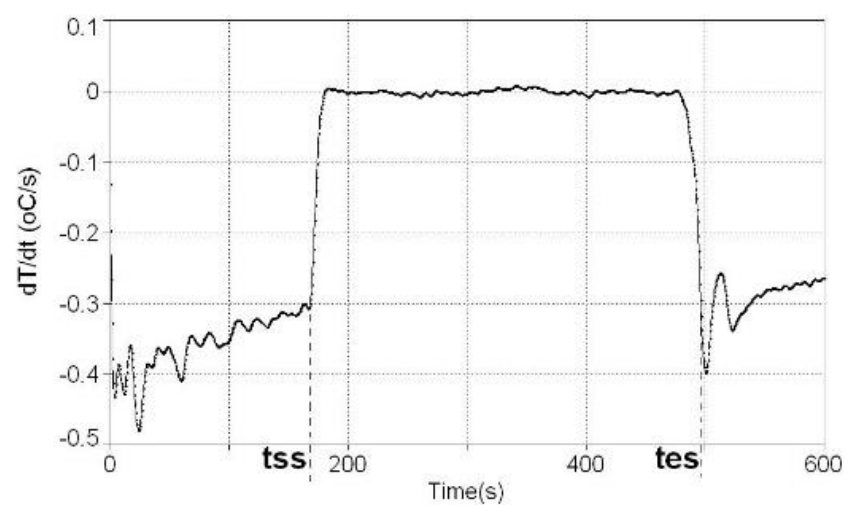

Figure 2. First derivative with respect to time of the cooling curve of zinc shown in Fig. 1(a) and graphical determination of the times of starts tss and end tes of solidification.

The first derivative of the metal cooling curvewas calculatedin order to identify the times of start, tss and end,tes of solidification, by applying the conventional criteria reported for the NTA [3].Fig. 2 shows a graphical example of this determination in the case of one of the zinc samples. Subsequently, the heat transfer coefficient was calculated as a function of temperature using the thermal information of the metal and mold cooling curves in the absence of phase change. 
Fig. 3(a) shows the sections of the experimental cooling curves that were used to calculate the heat transfer coefficient based on Eq. (3) in the case of one of the zinc samples. Fig. 3(b) shows the values generated for this coefficient as a function of temperature which were treated by numerical fitting to obtain an equation of $h$ as a function temperature. Table 3 shows the result of the numerical fitting in terms of equations of $h$ as a function of $T$, for the experimental runs .
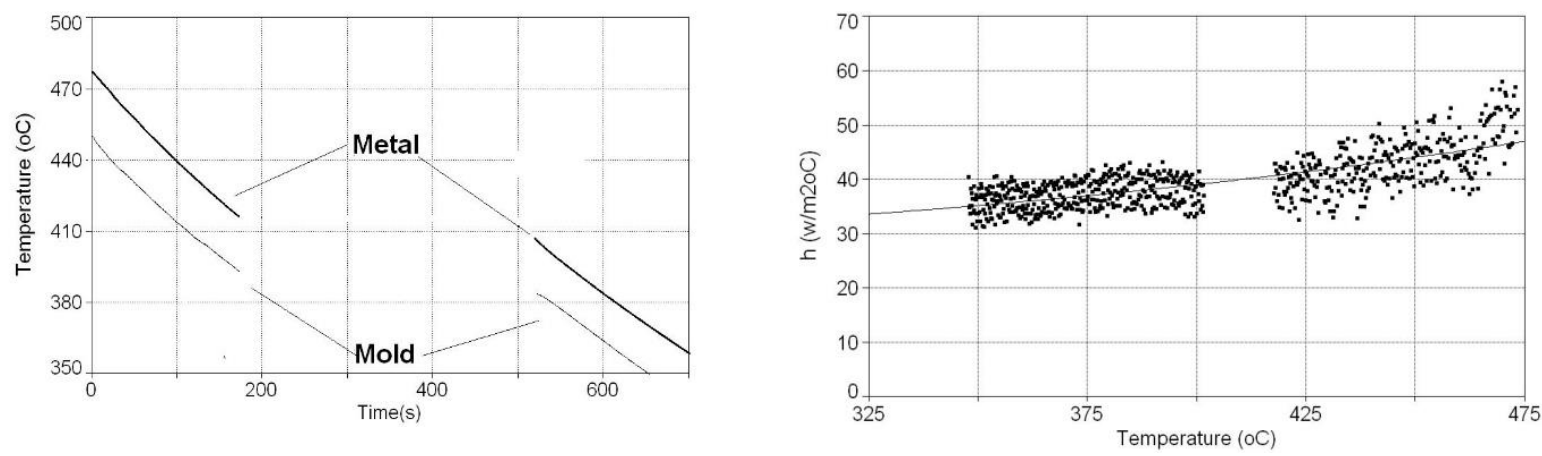

Figure 3. (a) Sections of the cooling curves show in Fig. 1(a) used to calculate $h$ using eq.(3); (b) Graphical values of the global heat transfer coefficient $h$, obtained as a function of temperature and numerical fitting line, corresponding to a cubic equation, see table 3.

Table3.-Expressions of the global heat transfer coefficient as a function of temperature obtained by numerical fitting for the six experimental runs

\begin{tabular}{l|l|l|l}
\hline Metal & $\mathbf{M} 1\left(\mathbf{W} / \mathbf{m} 2^{\circ} \mathbf{C}\right)$ & $\mathbf{M} 2\left(\mathbf{W} / \mathbf{m} 2^{\circ} \mathbf{C}\right)$ & $\mathbf{M} \mathbf{3}\left(\mathbf{W} / \mathbf{m} 2^{\circ} \mathbf{C}\right)$ \\
\hline Zinc & $\mathrm{h}=27.2+1.8 \mathrm{e}-7^{*} \mathrm{~T}^{\wedge} 3$ & $\mathrm{~h}=26.3+2.9 \mathrm{e}-7^{*} \mathrm{~T}^{\wedge} 3$ & $\mathrm{~h}=20.83+2.3 \mathrm{e}-7^{*} \mathrm{~T}^{\wedge} 3$ \\
\hline Tin & $\mathrm{h}=13.0+2.2 \mathrm{e}-4^{*} \mathrm{~T}^{\wedge} 2$ & $\mathrm{~h}=11.7+2.4 \mathrm{e}-4 \mathrm{~T}^{\wedge} 2$ & $\mathrm{~h}=15.1+2.6 \mathrm{e}-4 \mathrm{x}^{\wedge} 2$ \\
\hline \multicolumn{2}{l}{ M1:Sample 1;M2 : Sample 2; M3 : sample 3. }
\end{tabular}

Once the expressions of $h$ as a function of $T$ were obtained, they were validated using the known weights of zinc and of the metallic mold, by comparing the instantaneous flow of heat transferred by the zinc as a result of its temperature drop, represented by the term to the left of the equality in Eq. (2) with respect to the sum of the two terms shown to the right of the equality in eq. (2). Typical results of the evolution of heat flow calculated for each side of eq. (2) during experimental cooling of one of the zinc samples in the liquid state are shown in Fig. 4.

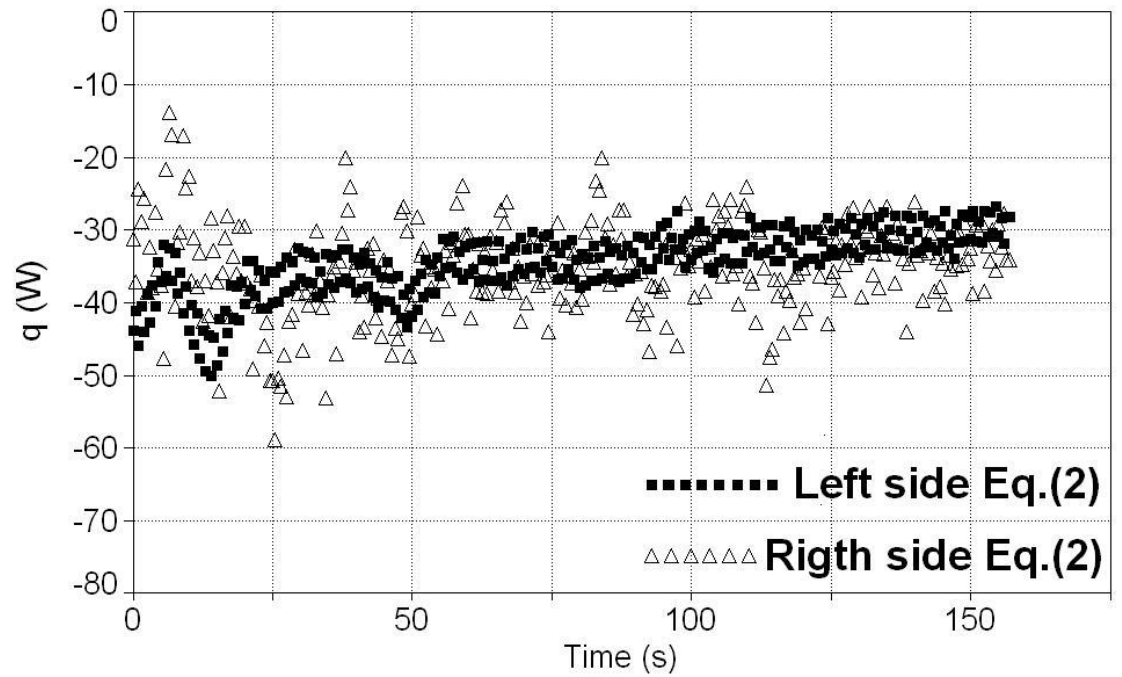

Figure 4. Calculated evolution of heat flow for each side of eq. (5) during experimental cooling of one of the zinc samples in the liquid state 
During the cooling of this sample, weighing 203 grams, contained in the stainless steel mold weighing $243 \mathrm{~g}$, the heat transferred by the zinc during its cooling in the liquid state, from $473.4 \mathrm{oC}$ to $420 \mathrm{oC}$, using the $\mathrm{Cp}$ show in table 2, is -5215 Joules while the sums of each of the two terms shown to the right of Eq. (2) during the same intervals are -12701 and 7353 joules which add up to -5348 joules which implies an approximate error of less than $3 \%$ with respect to the theoretical calculation. As it can be seen, the calculated values are very close.

Table 4 shows the values of the energy involved in the cooling of the three experimental samples in the liquid state as well as the errors found for the zinc and the tin samples during their cooling in the liquid cooling stage following the procedure mentioned above. This corresponds to the integration of eq. 2 from the first point registered for the cooling curve to the last point when the cooling of the liquid ends and comparing the total energy corresponding to the left side of eq. 2 with the energy calculated for the right side of eq.2 . As can be seen in this table, the error measured in all cases is less than $10 \%$ so apparently the global heat transfer coefficients calculated by the proposed methodology describe acceptably what happens in the system.

Table 4. Integration of the left side (LS) and right side of Eq. (5)to calculate the energy involved in the cooling of the liquid stage forthe three experimental samples of Zinc and Tin

\begin{tabular}{c|c|c|c|c|c|c|c}
\hline \multicolumn{3}{c|}{ Zinc } & \multicolumn{4}{c}{ Tin } \\
\hline & LSEq.(2) & RSEq.(2) & \%error & & LSEq.(2) & RSEq.(2) & \%error \\
\hline M1 & 5215 & 5348 & 2.6 & M1 & 6057 & 5975 & 1.3 \\
\hline M2 & 7828 & 7326 & 6.4 & M2 & 5562 & 5323 & 4.3 \\
\hline M3 & 5889 & 5578 & 5.3 & M3 & 5724 & 5594 & 2.3 \\
\hline
\end{tabular}

Once the global coefficient of heat transfer in the experimental system was known and validated, the next step of the methodology is to integrate Eq. (7) in order to obtain the value of the instantaneous latent heat released by the sample during solidification and the enthalpy of solidification. The heat capacity value used for the solidifying metal was the mean value of the heat capacities of the liquid and the solid metal evaluated at the melting temperature.

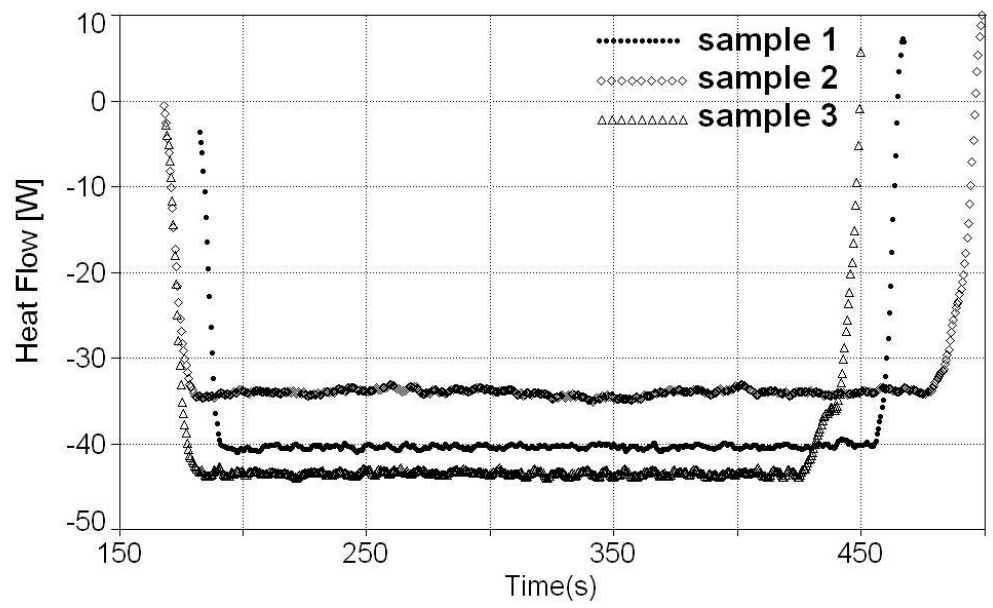

Figure 5. Instantaneous latent heat flow released as a function of time during solidification for the three zinc samples 
FIG. 5 shows the instantaneous latent heat flow released as a function of time typically calculated for each one of the samples. The integration of this flow during solidification provides the value of the energy released during the phase change, which divided by the weight of the sample provides the measured value of the latent heat of solidification per unit weight.The results obtained for the six experimental samples are shown in Table 5 . It can be seen that the values of enthalpy of solidification obtained from this method are close to the values reported in the sources of thermochemical data.

Table 5. Comparison between the calculated and reported values for the enthalpy of fusion for the three experimental samples of Zinc and Tin

\begin{tabular}{|c|c|c|c|c|c|}
\hline \multicolumn{3}{|c|}{$\begin{array}{c}\text { Zinc: } \Delta \text { HF Ref[10)= } 111426+/-1920 \\
\mathrm{~J} / \mathrm{Kg}\end{array}$} & \multicolumn{3}{|c|}{$\begin{array}{c}\text { Tin : } \Delta \text { HF Ref[10) }=59605+/- \\
1060\end{array}$} \\
\hline & $\Delta \mathrm{HF} \mathrm{J/Kg}$ & \%error & & $\Delta \mathrm{HF} \quad \mathrm{J} / \mathrm{Kg}$ & \%error \\
\hline M1 & 109954 & 1.4 & M1 & 58236 & 2.3 \\
\hline M2 & 104568 & 6.2 & M2 & 61391 & 3.0 \\
\hline M3 & 105350 & 5.4 & M3 & 61561 & 3.3 \\
\hline \multicolumn{3}{|c|}{ Zinc: $\Delta H F=106624+/-3300 \mathrm{~J} / \mathrm{Kg}$} & \multicolumn{3}{|c|}{ Tin : $\Delta H F=60396+/-2120 \mathrm{~J} / \mathrm{Kg}$} \\
\hline
\end{tabular}

In the final row of table 5 , it can be seen the dispersion of the latent heat value calculated by this method for the enthalpy of solidification of zinc and tin. These values when compared to the values and dispersions reported in the sources of thermodynamic data, shown in the first row of table 5 , are very close. This result suggests that the method proposed in this work provides a good approximation for the determination of latent heat of phase transformations, which is currently being verified by experimentation with other metals of commercial purity and alloys.

\section{Conclusions}

An alternative cooling curve analysis method, based in energy conservation equations, that takes into account the thermal role of the metallic mold containing the sample of interest, on the cooling process of the integral system metal sample/mold was tested experimentally in order to determine its ability to measure the latent heat of solidification of zinc and tin of commercial purity.

The values of the global coefficient of heat transfer used by the method and generated using the metal and mold cooling curves were validated by energy balances.

The results generated by the method for the latent heats of solidification of zinc and tin are close to those reported in the sources of thermodynamic data which suggests that this method could be used for the characterization of the solidification of metals and alloys.

\section{Acknowledgments}

The authors acknowledge DGAPA UNAM for financial support (Project IN116817), and to C. Aguilar, A. Harrup, F. Tena, MSc Students for their valuable work by performing the experiments . 


\section{REFERENCES}

1 Stefanescu Doru M. Thermal Analysis Theory and Aplications in Metalcasting , Int. J.of Metalcasting (2015), 9.1, 7-22.

2 Barlow, J. O., and D. M. Stefanescu, Computer-aided cooling curve analysis, Transactions of the American Foundryman Society, 1998, 349-354.

3 Cruz, H., Gonzalez C., Juarez A., Herrera M. And Juarez J. Quantification of the microconstituents formed during solidification by the Newton thermal analysis method, J. of Mater. Proc. Technol , 2006,178.1 128-134.

4 Fras E., Kapturkiewicz W., Burbielko A., Lopez HF., A new concept in thermal analysis of castings. Transactions of the American Foundrymen's Society, $1993,101,505-511$.

5 Baez J, Gonzalez C., Chavez M.R., Castro M., Juarez J., Fourier thermal analysis of the solidification kinetics in A356/SiCp cast composites, J.of Mater. Proc.Tech. 2004, 153-154, 531-536.

6 Gibbs, John W., and Patricio F. Mendez. "Solid fraction measurement using equationbased cooling curve analysis." ScriptaMaterialia 2008, 58.8 699-702.

$7 \mathrm{Xu}, \mathrm{J}$. F., et al. Comparison of baseline method and DSC measurement for determining phase fractions. Mater. Sci. and Tech.2012, 28.12 1420-1425.

8 Kamyabi-Gol, Ata, and Patricio F. Mendez. "The Evolution of the Fraction of Individual Phases During a Simultaneous Multiphase Transformation from Time-Temperature Data." Metall. Mater. Trans.A, 2015, 46.2, 622-638.

9 Erbaş, Kadir Can. "Analytically Solved Solid Fraction Model for the Newtonian Thermal Analysis of Casting." Metall. Mater.Trans. A , 2016, 47.6, 3026-3030.

10 Gale, William F., and Terry C. Totemeier, eds. Smithells metals reference book. 3th edition, Butterworth-Heinemann, 2003

11 Kubaschewski, Oswald, A. L. Evans, and Charles Benjamin Alcock, Metallurgical Thermochemistry, Pergamon Press Fifth edition, 1983. 